\title{
Clinical errors and medical negligence
}

\section{Femi Oyebode}

\begin{abstract}
This article discusses the definition, nature and origins of clinical errors and potential means of prevention. The relationship between clinical errors and medical negligence is examined, as are the characteristics of litigants and events that prompt litigation. Legal aspects of medical negligence are outlined and clinical situations most commonly associated with negligence claims are described. Probably no more than 1 in 7 adverse events in medicine results in a negligence claim and the factors that predict whether patients will resort to litigation include a prior poor relationship with the clinician and the feeling that they are not being kept informed. The actual rate of negligence claims in psychiatry is unknown, but it is rising. Clinicians must therefore be aware of the risks and of which areas of practice are most risky.
\end{abstract}

Towards the end of last year the National Patient Safety Agency published Medical Error: How to Avoid It All Going Wrong and What To Do If It Does (National Patient Safety Agency, 2005). This short publication includes accounts from leading doctors about clinical errors that they made at some point in their careers. It is a small but important development in the attempt to shift attitudes in medicine about clinical errors and how to respond to them. The thinking is, if these successful doctors (and they include the President of the General Medical Council, the President of the Royal College of Anaesthetists, and others) can own up to errors, maybe making a clinical error is not evidence of intractable incompetence. This publication is part of the ongoing process in the wake of the Chief Medical Officer's report An Organisation with a Memory (Department of Health Expert Group, 2000). In this report the Chief Medical Officer listed a number of facts about adverse events associated with medical care in the National Health Service (NHS). These included, for an average year:

- 1150 suicides by people who had been in contact with mental health services in the 12 months prior to the event

- 40 homicides by people in contact with mental health services in the 12 months prior to the event

- 125 deaths of women within 1 year of giving birth

- 20000 deaths within 30 days of surgery

- 7800 stillbirths and infant deaths.

The implicit assumption was that these untoward events were preventable and represented evidence of clinical error. The Chief Medical Officer further cited evidence from the 1991 Harvard Medical Practice Study and the 1995 Australian Health Care Study. These indicated that between $3.7 \%$ and $16.6 \%$ of inpatient episodes resulted in harmful adverse events and the proportion of in-patient episodes resulting in permanent disability or death was between $0.7 \%$ and $3 \%$. The extrapolation of these figures to the NHS was reported to give between 314000 and 1.4 million potential adverse events, based on 8.5 million in-patient episodes a year, and 60000-255000 potential instances of permanent disability or death. These are substantial numbers by any account. Aside from the potential harm to patients, there was also the matter of the direct cost of treating those harmed by these adverse events and, of course, the cost of litigation. The direct cost was estimated to be $£ 2$ billion in additional hospital days alone, with a further $£ 2.4$ billion of potential liability from existing and expected claims.

At about the same time that the Chief Medical Officer's report was published, on the other side of the Atlantic a report of the Quality Interagency Coordination Task Force to the US President on reducing medical errors repeated the list of potential and actual harms caused by medical treatment (Quality Interagency Coordination Task Force, 2000). The Task Force concluded that these errors cost as much as $\$ 29$ billion annually in lost income, disability and healthcare spending and that the consequences of medical mistakes are often more severe than the consequences of mistakes in other industries - leading to death or disability rather than inconvenience - underscoring the need for

Femi Oyebode is Professor and Head of the Department of Psychiatry at the University of Birmingham (Queen Elizabeth Psychiatric Hospital, Mindelsohn Way, Edgbaston, Birmingham B152QZ, UK. Email: Femi.Oyebode@sbmht.wmids.nhs.uk). He was Chief Examiner of the Royal College of Psychiatrists from 2002 to 2005, and is a member of the Council of the Medical Defence Union. He has an interest in clinical risk and medical negligence. 
aggressive action in this area. It quoted the results of a number of studies to illustrate the problem, for example that the average intensive care unit patient experienced almost two errors per day, and that this translated to a level of proficiency of about $99 \%$. One out of five of these errors was potentially serious or fatal. It estimated that if performance levels of $99.9 \%$ - substantially better than those found in the intensive care unit - applied to the airline and banking industries respectively, this would equate to two dangerous landings per day at $\mathrm{O}^{\prime} \mathrm{Hare}$ International Airport and 32000 cheques deducted from the wrong accounts per hour.

It is clear from the foregoing discussion that clinical errors have come to the attention of the wider public and politicians.

\section{Clinical error}

\section{Definition and patterns of error}

The US Institute of Medicine's report (Kohn et al, 1999) on improving the safety of the healthcare system defines clinical error as the failure of a planned action to be completed as intended or the use of a wrong plan to achieve an aim'. In other words, errors can arise in planning actions or in executing them. As examples of the types of clincial error shown in Box 1, Kohn et al listed adverse drug events and improper transfusions, surgical injuries and wrong-site surgery, suicides, restraint-related injuries or death, falls, burns, pressure ulcers and mistaken patient identity. They commented that high error rates with serious consequences are most likely to occur in intensive care units, operating rooms and emergency departments.

It is widely accepted that medication error is the most common and preventable cause of patient injury. This includes the giving of the wrong drug or dose, by the wrong route of administration, to the wrong patient or at the wrong time. There is evidence that in acute hospitals the incidence of adverse drug events is 6.5/100 admissions, and of these $1 \%$ are fatal, $12 \%$ life-threatening and $28 \%$ preventable (Bates et al, 1995b). These figures are similar for paediatric in-patient units (Kaushal et al, 2001), nursing homes for elderly people (Gurwitz et $a l, 2000)$ and clinics treating elderly out-patients (Gurwitz et al, 2003). Furthermore, it is estimated that there are 5.3 medication errors per 100 prescriptions. These include missing dose (53\%), dosage errors $(15 \%)$, frequency errors $(8 \%)$ and route errors $(5 \%)$, but only $1 \%$ of the total were associated with adverse drug events (Bates et al, 1995a). It is also estimated that the additional annual cost of adverse drug events in hospitalised patients in a 700-bed teaching hospital is US\$5.6 million. In addition to adverse drug events

\section{Box 1 Types of clinical error}

Diagnostic

- Error or delay in diagnosis

- Failure to use indicated investigations

- Use of inappropriate investigations

- Failure to act on results of investigations

Treatment

- Error in the performance of a procedure

- Error in administering a treatment

- Error in the dose of drug

- Avoidable delay in treatment

Preventive

- Failure to provide prophylactic treatment

- Inadequate follow-up

Other

- Failure of communication

- Equipment failure

- System failure

other adverse events in hospitalised patients include wound infections and technical complications. It is estimated that nearly half of all adverse events in hospitals are associated with surgical operations. Adverse events not associated with surgery included diagnostic mishaps, therapeutic mishaps (errors or omissions) and events occurring in accident and emergency departments (Leape et al, 1995).

Much of the data on medication errors is from the USA. However, in a recently reported study from a typical British teaching hospital over a 4-week period, prescribing errors were identified in $1.5 \%$ of cases, and $0.4 \%$ of these errors were serious. The majority of errors originated from prescribing decisions (Dean et al, 2002). There is little empirical data on clinical errors in psychiatric settings. However, there is no reason to believe that the general pattern within psychiatric settings would significantly differ from that in general medical settings.

\section{Explanatory models of human error}

There are two models of causation of human error, namely the person approach and the system approach. The person approach focuses on the errors of individuals, and is apt to accuse them of forgetfulness, inattention or moral failure. The system approach identifies the conditions and systems under which individuals work as the source of the error, with the aim of both understanding the origins of error and building defences to avert errors or to mitigate their effects (Reason, 2000).

The system approach acknowledges that the majority of clinical errors do not result from 
individual recklessness or the actions of a particular group (Kohn et al, 1999). The most common systems deficiencies identified as underlying clinical errors are failures in dissemination of drug knowledge and inadequate availability of patient information such as test results necessary for safe treatment (Leape et al, 1995).

There is little doubt that the person approach continues to hold sway and that the temptation to blame an identified individual is hardly resisted by institutions. None the less, much can be done to improve the work environment so as to reduce the likelihood of clinical error. Some possible tactics are listed in Box 2.

It is common to compare the healthcare arena to the airline industry or to 'high-reliability' organisations (Box 3) such as air traffic control centres, which have clearly unambiguous goals. Such comparison is probably misguided. The goals of a hospital are multiple and varied, and healthcare is immensely more complex than any of the organisations to which it is usually compared. The risk of adverse events and outcomes as a result of interaction with clinicians is compounded by the already increased risk of adverse outcome determined by disease. In other words, people are in hospital because they are ill. The processes and procedures they are exposed to in these circumstances are neither similar nor identical, but are determined by their unique histories and needs.

\section{Prevention}

There are numerous proposed strategies for reducing the incidence of clinical errors. The Institute of Medicine's report (Kohn et al, 1999) advocated establishing a national focus in order to create leadership and research tools to enhance the knowledge base about patient safety. It also advocated a nationwide public mandatory system for reporting errors that would help managers and clinicians to identify and learn from them. Furthermore, it called for improvement in safety

\section{Box 2 Tactics for reducing clinical error}

- Reduce the complexity of tasks

- Optimise information processing by the use of protocols or aids

- Automate wisely and as necessary

- Use of constraints, as in the delivery system of anaesthetic gases

- Mitigate unwanted side-effects of change, particularly when new techniques or treatments are first introduced

\section{Box 3 High-reliability organisations (Reason, 2000)}

In management parlance, high-reliability organisations are those that manage complex and demanding technologies so as to avoid catastrophic failures, while maintaining the capacity to meet periods of high peak demand. Examples include air traffic control centres, nuclear power plants and nuclear aircraft carriers.

Their defining characteristics are that they are complex, internally dynamic and, intermittently, intensely interactive organisations that perform exacting tasks under considerable pressure of time, yet have low incident rates and a relative lack of catastrophic failures. Under routine circumstances they are controlled in a hierarchical manner, but in an emergency the control shifts to experts on the spot.

through the actions of overseeing organisations, professional groups and others. Finally, it directly asked healthcare organisations to ensure safe practices at the level of delivery.

In the UK, the Chief Medical Officer's report (Department of Health Expert Group, 2000) called for changes in the NHS to include unified mechanisms for reporting and analysis when things go wrong; a more open culture in which errors or service failures can be reported and discussed; mechanisms for ensuring that, where lessons are identified, the necessary changes are put into practice; and a much wider appreciation of the value of the system approach in preventing, analysing and learning from errors. There is certainly convergence of approach and thinking across the Atlantic.

\section{Medical negligence}

The number of medical negligence claims does not match the number of cases subject to a clinical error. Localio et al (1991) reported as part of the Harvard Medical Practice Study that the overall rate of negligence claims per discharge was $0.13 \%$. This is likely to be far higher than the rate in the UK. Of the 280 patients in the study who had experienced adverse events caused by clinical error only 8 filed a medical malpractice claim. This gave an estimated ratio of adverse event to malpractice claim of 7.6:1. Localio et al concluded that this was a clear overestimate, as most of the events for which malpractice claims were made did not meet research criteria of adverse events due to clinical error. 
Box 4 What influences patients to make malpractice claims?

- A poor relationship with the healthcare provider or clinician before the alleged injury

- Television advertising by law firms

- Explicit recommendations by health providers or professionals to seek legal advice

- The impression of not being kept informed by the healthcare provider or clinician

- Financial concerns

Towse \& Danzon (1999) estimated that 90000 adverse clinical events, involving 13500 deaths, occur in the UK each year, but these result in only about 7000 claims and 2000 payments. During 1996-1997, medical negligence was estimated to have cost the NHS in England $£ 235$ million. According to Dyer (1999) negligence claims against general practitioners (GPs) rose 13-fold between 1989 and 1998. For example, in 1989 there were 38 claims against GP members of the Medical Protection Society, but by 1998 claims had risen to 500. The largest rise was in the number of actions that ultimately failed or were abandoned. However, it must be noted that estimates for negligence claims in the NHS are subject to revision. Fenn et al (2005) have argued that the estimates of medical negligence are an exaggeration and that, although the rate of growth has increased, it does not amount to the uncontrollable explosion sometimes reported.

Clearly, not all clinical errors result in malpractice claims. Box 4 shows the five major factors reported by Huycke \& Huycke (1994) as influencing patients' decisions to make a claim: only three of these might be under the direct control of the clinician involved. This was an American study that may not be directly applicable to the UK. This is particularly relevant to the final point in the list, as financial concerns seemed to be a major reason prompting individuals in employment to pursue a negligence claim when outstanding medical bills equalled or exceeded $50 \%$ of their annual income.

Rothschild et al (2002) found that the adverse drug events most likely to result in negligence claims involved the use of antibiotics, antidepressants, antipsychotics, cardiovascular drugs and anticoagulants. The events recorded were often severe, costly and preventable and about half involved out-patients.

\section{Public attitudes to medical error}

The most worrying aspect of the recent changes in public attitude to clinical error is the increased criminalisation of fatal medical errors. Ferner (2000) reported the dramatic increase in the charge of manslaughter against doctors in the UK between 1970 and 1999. In each of the periods 1970-1979 and 1980-1989 there were only two cases. In the period 1990-1999 there were 13 cases, involving 17 doctors. Ferner concluded:

'For most errors ... the criminal law is unsatisfactory. Convicting doctors of manslaughter may satisfy a desire for retribution, but deters careful consideration of the ways of preventing tragedies from recurring.'

The increase is attributed to our society's changed attitude towards the notion of gross negligence. For example, in 1925 a Court of Appeal ruled that in a case of gross negligence the accused's behaviour must go beyond that requiring mere compensation and must show such disregard for the life and safety of others as to amount to a crime against the state and conduct deserving of punishment (Holbrook, 2003). In a 19th-century case, the court noted that:

'if there was only the kind of forgetfulness which is common to everybody, or if there was a slight want of skill ... it would be wrong to proceed against a man criminally in respect of such injury'.

The court then gave as an example of gross negligence a surgeon who operated while drunk (Holbrook, 2003).

\section{Deterrants}

It might be argued that negligence claims and the increasing amounts of damages paid out should serve to deter clinical errors, but there is little evidence to this effect. Although medical practitioners may alter their practice such that it appears to be more legally defensible, there does not appear to be an accompanying decrease in either claims or errors. Furthermore, the idea that healthcare providers would participate in quality improvement schemes and clinical error reduction initiatives because of a desire to curb the spiralling costs of negligence claims is not borne out by the facts (Mello \& Brennan, 2002). This is partly due to the misfit between who is injured by medical negligence and who sues, but also to the externalisation of the costs of negligence to third parties (i.e. insurers bear the brunt of the cost). Thus, the incentive to healthcare providers to act to reduce clinical errors may not be particularly strong. However, even if it were true that healthcare providers acted vigorously to reduce the likelihood of clinical errors by, for example, adopting and insisting on the use of evidence-based guidance as part of clinical governance or quality improvement schemes, there are questions about how far this would itself influence the determination of medical negligence. 


\section{Justifying a claim of medical negligence}

Three conditions must be met in a case of medical negligence. The individual bringing the action must show first that the doctor owed the complainant a duty of care, second that this duty was breached by failure to provide the required standard of medical care and third that this failure caused the complainant injury and/or loss for which compensation is payable and which was both foreseeable and reasonably avoidable (Box 5).

In the UK, the standard of care is primarily determined by the Bolam test:

'The test is the standard of the ordinary skilled man exercising and professing to have that special skill' (Bolam v. Friern Hospital Management Committee, 1957).

The Bolam test recognises that there might be several schools of thought regarding proper medical management, which allows medical practitioners to rebut a charge of negligence if they can show that they acted in accordance with practice approved by a body of other responsible practitioners. A more recent refinement to the Bolam test requires that, to be acceptable to the courts, the standard of practice determined by the test must be amenable to logical analysis (Bolitho v. City and Hackney Health Authority, 1997).

The question is how far clinical guidance can influence the decision of courts with respect to standard of care. Hurwitz (2004) argues that if courts were required to consult guidelines because they provide standards justified by evidence rather than custom, this would strengthen what he refers to as the normative dynamic of the law, shifting the focus from what it is customary to do to what ought to be done. The risk as Hurwitz sees it is of a slavish adherence to clinical guidelines. The NHS Executive appears to appreciate this, stating that:

'clinical guidelines can only assist the practitioner; they cannot be used to mandate, authorise or outlaw treatment options. Regardless of the strength of the evidence, it will remain the responsibility of the practising clinician to interpret their application' (Department of Health, 2004).

Box 5 The three requirements of medical negligence

1 A duty of care

2 Failure to provide the standard of care needed to fulfil this duty

3 Resultant injury and/or loss to the patient that was foreseeable, reasonably avoidable and for which compensation is payable

\section{Illustrative negligence claims in psychiatry}

There is no readily available database that allows clinicians to judge the risk of a negligence action that a particular clinical activity carries. The situation is compounded by the fact that cases that go to trial and are therefore in the public domain do not necessarily indicate the actual risk of particular areas of clinical work. Many more cases are settled out of court or are discontinued and it is these that would give a clearer picture of the pattern of negligence claims in psychiatry.

The following examples of areas of practice that commonly lead to negligence claims are drawn from the literature as well as from experience working within clinical risk management in the NHS and providing expert advice and medico-legal reports. These examples are not exhaustive.

\section{Diagnostic error}

Error or delay in diagnosis of physical illness

Diagnostic error might involve the misdiagnosis of a physical disease as a psychiatric disorder or a delay in the diagnosis of a physical illness because of the confounding effects of a psychiatric disorder. Examples include delayed diagnosis of carcinoma of the pancreas in the context of depression, misdiagnosis of insulinoma as panic disorder or of encephalitis as acute psychosis. These cases rely on the primacy usually accorded to physical disease in relation to psychiatric illness. In such situations it is usually alleged that there was a failure of adequate assessment, including the use of appropriate investigations. In retrospect, the clinical diagnosis appears self-evident and a psychiatric hospital admission obviously inappropriate. Potential defences in these cases are outlined in Box 6 .

\section{Suicides}

Suicides are common causes of negligence claims. In a case of foreseeable but unforeseen suicide it is usually alleged that the doctor failed properly to assess the patient and thus did not recognise the risk. In the case of foreseeable but unprevented suicide the allegation is of failure properly to supervise or restrain a patient whose risk of suicide is already recognised. Premature discharge, negligent discharge or unjustified freedom of movement can also be alleged as the basis of a foreseeable but unforeseen suicide. There are a number of potential defences against these allegations, some of which are listed in Box 7 . 
Box 6 Defences against allegations of error or delay in diagnosis of physical illness

- The established literature on the association between conditions, as between carcinoma of the pancreas and depression

- Evidence of collaboration between physicians and psychiatrists to disentangle the origins of particular symptoms

- Evidence of appropriate investigations

- Evidence of due diligence in assessing and treating the patient, including the frequency of contact and adequacy of clinical notes

Failure to investigate properly or act on results of investigations

This may involve cases in which the necessary investigations were not carried out or in which clear evidence of abnormal results that demanded further action was not acted on. Examples include an individual thought to have attempted suicide by jumping who was not sent for an X-ray to investigate possible spinal injury and a patient taking carbamazepine whose low white cell count was not acted on.

\section{Treatment errors}

Error in administering treatment

The use of combinations of treatments that are recognised as likely to result in an adverse event is often the subject of litigation. For example, the combination of lithium and diuretics can result in elevated and toxic lithium levels. Most negligence claims regarding these drugs arise when a GP prescribes a diuretic to a patient who is on lithium and no one adequately monitors lithium levels or

Box 7 Defences against allegations of failure to prevent suicide

- Clinician acted in concordance with accepted clinical practice

- The lack of knowledge of suicidality was reasonable

- There was a justifiable allowance of freedom of movement given that the individual was on an open ward

- Clinician's decision was reasonable regarding diagnosis and/or course of treatment

- Extraordinary circumstances precluded or circumvented reasonable precautions or restraint

(Simon, 1992) acts on the results of monitoring. It is not unusual for the patient to continue to attend a psychiatric clinic following the prescription of a diuretic, and psychiatrists may become involved in the litigation because of unclear arrangements between the GP and the psychiatrists about who should be monitoring lithium levels. Thus, the psychiatrist may also fail to monitor levels adequately or to act in response to the results of monitoring.

The defence of these cases can fail because national guidance on regular monitoring is not followed and this signals a technical breach of duty.

Error in the continuing prescription of treatments that are indicated for brief use

These claims can arise from the continuing prescription of drugs such as clomethiazole and diazepam. In the case of clomethiazole, the claims arise when the prescription of the drug during an inpatient episode is continued indefinitely by the GP and/or is not stopped during subsequent out-patient appointments or psychiatric hospital admissions. These claims are often initiated against the GP but can later come to involve the psychiatrist.

\section{Antipsychotic drugs and dyskinesia}

Claims are made against psychiatrists for the continuing and prolonged prescription of antipsychotic drugs, usually typical antipsychotics, for bipolar mood disorder. The claims arise when patients develop irreversible tardive dyskinesia as a side-effect of the drugs, and they rest on the alleged inappropriate use of antipsychotics as prophylactic agents in bipolar disorder.

\section{Conclusions}

This article has discussed the increasing public awareness of clinical errors and the nature and pattern of these errors. There is little empirical investigation into clinical errors in psychiatry but there is no reason to think that their pattern of occurrence substantially differs from that in other areas of medicine. This means that medication errors, followed by procedural errors, are likely to be most common in psychiatry.

There is little correlation between the incidence of clinical errors and that of medical negligence claims. Probably no more than 1 in 7 adverse events in medicine results in a negligence claim. It is important to recognise that many negligence claims would not normally be regarded by medical practitioners as arising from adverse events. None the less, the factors that predict that a patient will resort to litigation include a prior poor relationship with the 
clinician and the feeling that the patient is not being kept informed. Negligence claims in psychiatry are becoming more common and clinicians should therefore be aware of the risks that they carry and know in which areas of practice the risk is greatest.

\section{Declaration of interest}

None.

\section{References}

Bates, D. W., Boyle, D. L., Vander Vliet, M. B., et al (1995a) Relationship between medication errors and adverse drug events. Journal of General Internal Medicine, 10, 199-205.

Bates, D. W., Cullen, D. J., Laird, N., et al (1995b) Incidence of adverse drug events and potential adverse drug events. Implications for prevention. JAMA, 274, 29-34.

Dean, B., Schachter, M., Vincent, C., et al (2002) Prescribing errors in hospital inpatients: their incidence and clinical significance. Quality and Safe Health Care, 11, 340-344.

Department of Health (2004) Implementation of NICE Guidance. London: Department of Health.

Department of Health Expert Group (2000) An Organisation with a Memory. Report of an Expert Group on Learning from Adverse Events in the NHS chaired by the Chief Medical Officer. London: Department of Health.

Dyer, C. (1999) GPs face escalating litigation. BMJ, 318, 830 .

Fenn, P., Diacon, S., Gray, A., et al (2005) Current cost of medical negligence in NHS hospitals: analysis of claims database. BMJ, 320, 1567-1571.

Ferner, R. E. (2000) Medication errors that have led to manslaughter charges. BMJ, 321, 1212-1216.

Gurwitz, J. H., Field, T. S., Avorn, J, et al (2000) Incidence and preventability of adverse drug events in nursing homes. American Journal of Medicine, 109, 87-94.

Gurwitz, J. H., Field, T. S., Harrold, L. R., et al (2003) Incidence and preventability of adverse drug events among older persons in the ambulatory setting. JAMA, 289, 1107-1116.

Holbrook, J. (2003) The criminalization of fatal medical mistakes. $B M I, 327,1118-1119$.

Hurwitz, B. (2004) How does evidence based guidance influence determinations of medical negligence? BMJ, 329, 1024-1028.

Huycke, L. I. \& Huycke, M. M. (1994) Characteristics of potential plaintiffs in malpractice litigation. Annals of Internal Medicine, 120, 792-798.

Kaushal, R., Bates, D. W., Landrigan, et al (2001) Medication errors and adverse drug events in pediatric inpatients. JAMA, 285, 2114-2120.

Kohn, L. T., Corrigan, J. M. \& Donaldson, M. S. (eds) (1999) To Err is Human: Building a Safer Health System. Washington, DC: National Academies Press.

Leape, L. L., Bates, D. W., Cullen, D. J., et al (1995) Systems analysis of adverse drug events. JAMA, 274, 35-43.

Localio, A. R., Lawther, A. G., Brennan, T. A., et al (1991) Relation between malpractice claims and adverse events due to negligence. Results of the Harvard Medical Practice Study III. New England Journal of Medicine, 325, 245-251.

Mello, M. M. \& Brennan, T. A. (2002) Deterrence of medical errors: theory and evidence for malpractice reform. Texas Law Review, 80, 1595.

National Patient Safety Agency (2005) Medical Error: How to Avoid It All Going Wrong and What To Do If It Does. London: NPSA. Available at http:/ / www.saferhealthcare.org.uk/IHI/ Products/Publications/MedicalError.htm

Quality Interagency Coordination Task Force (2000) Doing What Counts for Patient Safety: Federal Actions to Reduce Medical Errors and their Impact. Rockville, MD: Quality Interagency Coordination Task Force.

Reason, J. (2000) Human error: models and management. BMJ, $320,768-770$.

Rothschild, J. M., Federico, F. A., Gandhi, T. K., et al (2002) Analysis of medication-related malpractice claims: causes, preventability, and costs. Archives of Internal Medicine, 162, 2414-2420.

Simon, R. I. (1992) Clinical psychiatry and the law. Washington, DC: American Psychiatric Association.

Towse, A. \& Danzon, P. (1999) Medical negligence and the NHS: an economic analysis. Health Economics, 8, 93-101.

Bolam v. Friern Hospital Management Committee [1957] 2 All ER 118-128.

Bolitho v. City and Hackney Health Authority [1997] 3 WLR 1151-1161.

\section{MCQs}

1 In a case of medical negligence:

a there must be evidence of a breach of duty of care

$\mathrm{b}$ the negligence involves injury and/or loss that is a result of breach of duty

c compensation must be payable for the injury

$d$ the injury caused may not be forseeable or preventable

e the standard of care is determined by the Bolam test.

2 Factors known to influence the decision to proceed to litigation for clinical errors include:

a the severity of resulting harm

$b$ the site of the injury

c the quality of the relationship between patient and doctor

$\mathrm{d}$ the need to seek compensation because of financial difficulties

e advertising by personal injury companies.

3 Potential defences against an action following foreseeable suicide include:

a accepted clinical practice

b reasonable lack of knowledge of suicidality

c justifiable allowance of freedom of movement

d low nursing staff levels

e absence of intensive care ward.

4 Tactics to reduce clinical error include:

a increasing the complexity of tasks

b use of technical constraints

c use of protocols

d use of automated systems

e reducing the complexity of tasks.

5 Characteristics of high-reliability organisations include:

a complex tasks

$\mathrm{b}$ intense interactive processes

c continuous performance of exacting tasks

d high rate of incidents

e low rates of catastrophic failures.

\begin{tabular}{|c|c|c|c|c|}
\hline \multicolumn{5}{|c|}{ MCQ answers } \\
\hline 1 & 2 & 3 & 4 & 5 \\
\hline a $\mathrm{T}$ & a $F$ & a $\mathrm{T}$ & a $F$ & a $\mathrm{T}$ \\
\hline $\mathrm{b} \mathrm{T}$ & $\mathrm{b} F$ & b $\mathrm{T}$ & $\mathrm{b} \mathrm{T}$ & $\mathrm{b} \mathrm{T}$ \\
\hline c $\mathrm{T}$ & c $\mathrm{T}$ & c $\mathrm{T}$ & c $\mathrm{T}$ & c $\mathrm{F}$ \\
\hline d F & $\mathrm{d} \mathrm{T}$ & d F & $\mathrm{d} T$ & d F \\
\hline e $\mathrm{T}$ & e $\mathrm{T}$ & e F & e $\mathrm{T}$ & e $\mathrm{T}$ \\
\hline
\end{tabular}

